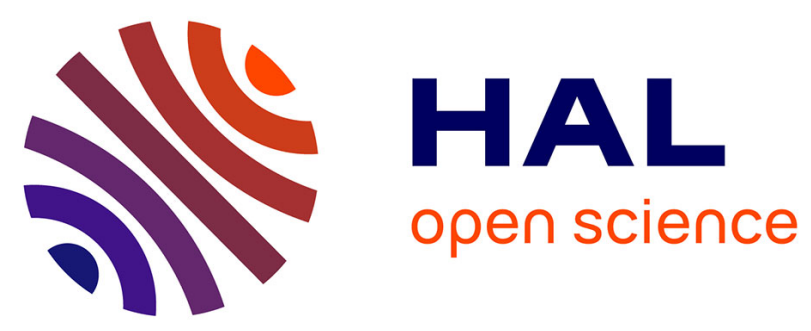

\title{
The use of the hypo-osmotic swelling test, water test, and supravital staining in the evaluation of drone sperm
}

Zekariya Nur, Selvinar Seven-Cakmak, Burcu Ustuner, Ibrahim Cakmak, Melih Erturk, Charles Abramson, Hakan Sağirkaya, Mustafa Soylu

\section{- To cite this version:}

Zekariya Nur, Selvinar Seven-Cakmak, Burcu Ustuner, Ibrahim Cakmak, Melih Erturk, et al.. The use of the hypo-osmotic swelling test, water test, and supravital staining in the evaluation of drone sperm. Apidologie, 2011, 43 (1), pp.31-38. 10.1007/s13592-011-0073-1 . hal-01003610

\section{HAL Id: hal-01003610 https://hal.science/hal-01003610}

Submitted on 1 Jan 2011

HAL is a multi-disciplinary open access archive for the deposit and dissemination of scientific research documents, whether they are published or not. The documents may come from teaching and research institutions in France or abroad, or from public or private research centers.
L'archive ouverte pluridisciplinaire HAL, est destinée au dépôt et à la diffusion de documents scientifiques de niveau recherche, publiés ou non, émanant des établissements d'enseignement et de recherche français ou étrangers, des laboratoires publics ou privés. 


\title{
The use of the hypo-osmotic swelling test, water test, and supravital staining in the evaluation of drone sperm
}

\author{
Zekariya Nur ${ }^{1}$, Selvinar SEVEN-CAKMAK ${ }^{2}$, Burcu Ustuner ${ }^{1}$, Ibrahim CAKMAK ${ }^{3}$, \\ Melih Erturk ${ }^{1}$, Charles I. Abramson ${ }^{4}$, Hakan SaĞIRKaya ${ }^{1}$, Mustafa Kemal Soylu ${ }^{1}$ \\ ${ }^{1}$ Department of Reproduction and Artificial Insemination, Faculty of Veterinary Medicine, Uludag University, \\ 16059 Gorukle, Bursa, Turkey \\ ${ }^{2}$ Uludag University Loj, Bursa, Turkey \\ ${ }^{3}$ Beekeeping Development-Application and Research Center, Uludag University, M. Kemalpasa MYO, Bursa, \\ Turkey \\ ${ }^{4}$ Laboratory of Comparative Psychology and Behavioral Biology, Departments of Psychology and Zoology, \\ Oklahoma State University, Stillwater, OK, USA
}

Received 13 February 2011 - Revised 16 May 2011 - Accepted 24 June 2011

\begin{abstract}
The aim of the present study was to investigate the suitability of the water test and hypo-osmotic swelling (HOS) test for analyzing honeybee semen. In particular, the relationships between these tests of the integrity of the sperm plasma membrane and tests of sperm motility and sperm viability were measured using SYBR-14/PI. To this end, semen was obtained from mature drones (16 days or older) collected from four colonies. The means of the per-drone sperm concentration, sperm motility, and live spermatozoa were $1.47 \times$ $10^{6}, 76.0 \%$, and $87.2 \%$, respectively. The percentage of spermatozoa with swollen tails was $92.2 \%$ as measured with the water test. With the HOS tests at 50,100 , and $150 \mathrm{mOsm} / \mathrm{kg}$, the percentages of spermatozoa with swollen tails were $94.2 \%, 90.5 \%$, and $85.6 \%$, respectively, after a 30 -min incubation and $92.2 \%, 90.5 \%$, and $88.0 \%$, respectively, after a 60 -min incubation. It was observed that subjecting honeybee spermatozoa to a hypo-osmotic solution resulted in clearly identifiable swollen-tail spermatozoa. The percentages of swollen-tail spermatozoa obtained using the water and HOS tests were higher than the percentages of viable and motile spermatozoa. Similar results were obtained using the water test and the HOS test at $50 \mathrm{mOsm} / \mathrm{kg}$. It was concluded that HOS and water tests are suitable and simple measures of the functional integrity of the plasma membranes of bee spermatozoa, and they may be useful additions to standard methods of semen evaluation in mammals.
\end{abstract}

bee semen / HOS test / water test / viability

\section{INTRODUCTION}

The quality of drone semen affects the mating success of queen bees. Since the development of instrumental insemination of honeybee (Apis mellifera) queens in the 1930s, there has been an interest in the evaluation and

Corresponding author: Z. Nur, nurzek@uludag.edu.tr Manuscript editor: Klaus Hartfelder in vitro storage of semen (Collins and Donoghue 1999). The process of fertilization involves complex biochemical and physiological events that are not completely reflected in traditional measures of concentration, motility, and morphology. Because the functional activity of the plasma membrane is crucial for the viability and fertilizing ability of spermatozoa, it is important to assess the structural and functional activity of the sperm membrane (Hafez 1993). Therefore, various tests have been developed to evaluate the 
functional and structural integrity of the mammalian sperm membrane, including supravital stains, hypo-osmotic swelling (HOS) test, water test, zona-free hamster ova test, and the cervical mucus penetration test (Hafez 1993). Unfortunately, most of these tests have not been adapted to the semen of non-mammals (e.g., bees and birds).

Various tests have been developed to evaluate the functional and structural integrity of drone spermatozoa. The tests include measures of sperm concentration, motility, and viability (Collins and Donoghue 1999). Several fluorescent stains have been effectively used in combination to assess sperm viability in mammalian, avian, and honeybee species (Collins and Donoghue 1999). Unfortunately, falsenegative and false-positive results accompany most of these biophysical procedures (Hafez 1993). In addition, most of the procedures require specialized equipment, significant expense, a large time commitment, and skilled personnel (Malmgren 1992).

The HOS and water tests have been effectively used to assess the functional integrity of mammalian sperm plasma (Jeyendran et al. 1984; Lomeo and Giambersio 1991; Nur et al. 2004, 2005; Kumi 1993), but to the best of our knowledge, no studies have used the HOS or water tests to investigate honeybee semen. The HOS test was developed by Jeyendran et al. (1984) to evaluate the functional integrity of sperm membranes. This test is based on the semi-permeability of the intact cell membrane, which allows the sperm to swell under hypoosmotic conditions. Tail swelling from the exposure of spermatozoa with intact plasma membranes to hypo-osmotic solution indicates that the transport of water across the membranes is occurring normally and the functional integrity of the membrane has been preserved (Jeyendran et al. 1984). The water test was also developed to evaluate sperm functional integrity by Lomeo and Giambersio (1991) and Fuse et al. (1993); this test uses distilled water as a hypo-osmotic solution. Fuse et al. (1993) have suggested that the water test is simpler and faster than the HOS test.
The aims of this study were (1) to assess the response of the drone semen to the HOS and water tests and (2) to examine the association of these responses with other semen parameters (i.e., concentration, motility, and viability).

\section{MATERIALS AND METHODS}

Experiments were performed in the Laboratory of Andrology in the Department of Reproduction and Artificial Insemination at the Faculty of Veterinary Medicine, Uludag University, Bursa, Turkey, in July 2009.

\subsection{Animals}

Drones were reared in colonies established with a drone wax foundation in May 2009. Mature drones (16 days or older) were collected from four colonies and brought to the laboratory.

\subsection{Semen collection and dilution}

Semen was collected from each drone $(n=110)$ by holding the head and thorax and gently squeezing the abdomen (Collins and Donoghue 1999). For semen collection at a 1:1 ratio, $0.8 \mu \mathrm{L}$ of saline solution was drawn into a Schley syringe tip 1.10 (Schley Instrumental Insemination equipment, Lich, Germany) under a stereo microscope, followed by approximately $0.8 \mu \mathrm{L}$ of semen (one drone). The collected semen from at least two drones was placed in a $1.5-\mathrm{mL}$ Eppendorf tube. A total of 51 pooled semen samples were used for the experiments.

Following semen collection, the samples were analyzed for sperm motility (Taylor et al. 2009), concentration (Taylor et al. 2009), viability (Taylor et al. 2009), and sperm plasma integrity using both the water test (Lomeo and Giambersio 1991) and the HOS test (Jeyendran et al. 1984).

\subsection{Sperm motility}

Sperm motility was assessed by examining a drop of diluted ejaculate, covered with a cover slip under a phase-contrast microscope at $\times 400$ magnification. Sperm motility was scored on a scale of 0 to 5 
corresponding to $0 \%, 20 \%, 40 \%, 60 \%, 80 \%$, and $\geq 95 \%$ of the observed population being motile, respectively (Taylor et al. 2009).

\subsection{Sperm concentration}

To measure sperm concentration, $2.5 \mu \mathrm{L}$ of diluted pooled semen was further diluted with $497.5 \mu \mathrm{L}$ of distilled water and mixed by inversion. Sperm concentration was determined with a hemocytometer (Ileri et al. 2000). In order to calculate concentrations per drone, the obtained measurements were divided by the number of drones whose semen was included in the pooled ejaculates.

\subsection{Sperm viability}

The viability of drone spermatozoa was assessed using the live/dead fluorescent stains SYBR-14 and propidium iodide (PI) (LIVE/DEAD Sperm Viability Kit [L-7011], Invitrogen-Molecular Probes). The manufacture's protocol was slightly modified using a sample that was less than $1 \mathrm{~mL}$ and using less PI.

Stain stock solution was prepared by diluting $20 \mu \mathrm{L}$ of SYBR-14 in $980 \mu \mathrm{L}$ of DMSO, whereas PI was used at full strength $(1.6 \mathrm{mg} / \mathrm{mL})$; both stains were stored at $-20^{\circ} \mathrm{C}$. Prior to staining, $10 \mu \mathrm{L}$ of collected semen was further diluted with $290 \mu \mathrm{L}$ of saline solution and added to an Eppendorf tube containing $8 \mu \mathrm{L}$ of SYBR-14 solution and incubated at room temperature for $5 \mathrm{~min}$. Following the incubation period, $2 \mu \mathrm{L}$ of PI were added to the sperm-stain mixture and further incubated in the dark for $5 \mathrm{~min}$. After incubation, one drop of the stained sample was smeared and immediately examined under a fluorescence microscope (BX51, Olympus Inc., Japan) with a multiple fluorescence filter (UDM-DA/FI/TX2) at 460-490-nm excitation and with a $530-\mathrm{nm}$ barrier. Viability was assessed by scoring 100 sperm cells in random fields. Red cells were scored as dead and green cells as live (Figure 1).

\subsection{HOS test}

The functional integrity of drone sperm membrane was evaluated using the HOS test, which was developed by Jeyendran et al. (1984) for human sperm. Before the test, the efficacy of the HOS test was verified using a fructose and Na-citrate solution with different osmolarities $(50,100$, and $150 \mathrm{mOsm} / \mathrm{kg}$ ). For this purpose, $1.0 \mu \mathrm{L}$ of drone semen was added to $250 \mu \mathrm{L}$ of one of the hypoosmotic solutions and incubated at room temperature for $60 \mathrm{~min}$. At 30-min intervals, one drop of incubated semen was placed on a glass slide, covered with a cover slip, and evaluated under phase-contrast microscope $(\times 40)$. Microscope fields were selected randomly. At least 100 spermatozoa were evaluated per slide, and the percentages of spermatozoa with swollen tails were calculated (Nur et al. 2005).
Figure 1. Bee spermatozoa after staining with SYBR-14/PI (X100). $L$ Live (green) and $D$ dead (red).

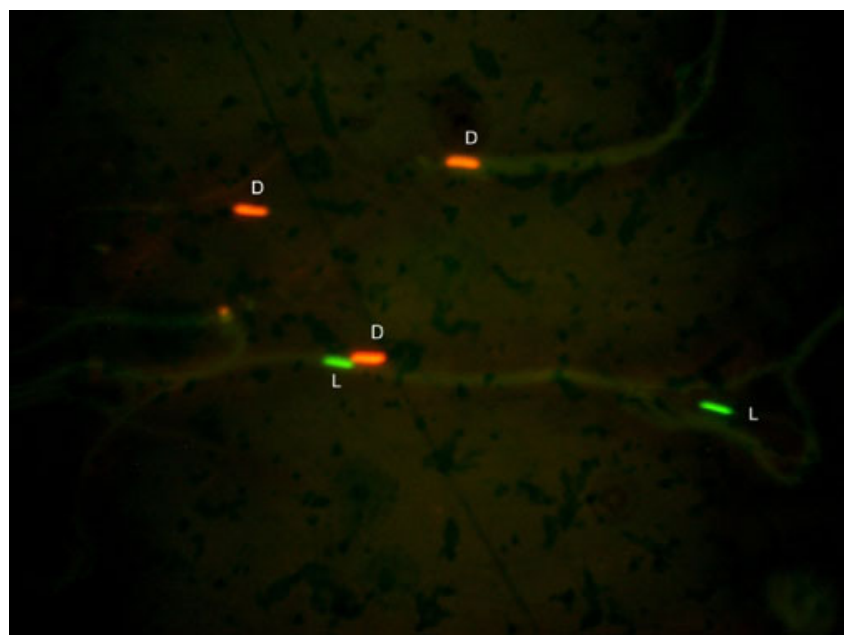




\subsection{Water test}

A volume of $1.0 \mu \mathrm{L}$ of semen was added to $250 \mu \mathrm{L}$ of distilled water and incubated at room temperature for $5 \mathrm{~min}$. Immediately after the incubation, one drop of semen was placed on a glass slide, covered, and evaluated under a phase-contrast microscope $(\times 400)$. Microscope fields were selected randomly. At least 100 spermatozoa were evaluated per slide, and the percentages of swollen tail spermatozoa were calculated (Nur et al. 2005).

\subsection{Statistical analyses}

The Wilcoxon rank-sum test was used to compare the mean percentages of motile spermatozoa, live/dead spermatozoa obtained with the SYBR-14/PI, and swollen spermatozoa obtained with the HOS and water tests. The Pearson correlation was calculated to evaluate the relationships among motility, viability, and the presence of swollen tails based on the water and HOS tests. All data were analyzed with the SPSS statistical package (SPSS 10.0 for Windows; SPSS, Chicago, IL, USA), and a difference was considered significant at the $P<0.05$ level.

\section{RESULTS}

The means of per-drone sperm concentration, sperm motility, and live spermatozoa were $1.47 \times 10^{6}, 76.0 \%$, and $87.2 \%$, respectively. Live honeybee spermatozoa showed morphological changes, as evidenced by curling/swelling, when exposed to hypo-osmotic conditions in the water and HOS tests (Figure 2). The percentage of swollen-tail spermatozoa based on the water test was $92.2 \%$. With the HOS test, the percentages at 50,100 , and $150 \mathrm{mOsm} / \mathrm{kg}$ were $94.2 \%, 90.5 \%$, and $85.6 \%$, respectively, after a 30 -min incubation and $92.2 \%, 90.5 \%$, and $88.0 \%$, respectively, after a 60 -min incubation. The differences in motility, the fraction of live spermatozoa, and the percentages of swollen-tail spermatozoa obtained based on the water and HOS tests for different osmolarities and incubation times were calculated (Table I). The percentage of sperm motility was lower than in viable spermatozoa using SYBR-14/PI treatment, and percentage of swollen-tail spermatozoa were highest in the water and HOS test $(P<0.05)$. The proportion of viable spermatozoa obtained using the SYBR14/PI treatment was lower than the proportion of swollen-tail spermatozoa based on the water and HOS tests at 50 and $100 \mathrm{mOsm}$ for both incubation times $(P<0.001)$. There was no significant difference between the fraction of swollen-tail spermatozoa obtained using the water test and the HOS test at 50 mOsm $(P>$ $0.05)$. An increase in the osmolarities used in the HOS test resulted in a decrease in the percentage of swollen-tail spermatozoa. The mean percentage of swollen-tail spermatozoa measured with the HOS test using 50 and $150 \mathrm{mOsm}$ and a 60-

Figure 2. Swollen-tail bee spermatozoa after subjection to hypo-osmotic solution $(\times 40)$. IPM Intact plasma membrane, $D M P$ damaged plasma membrane.

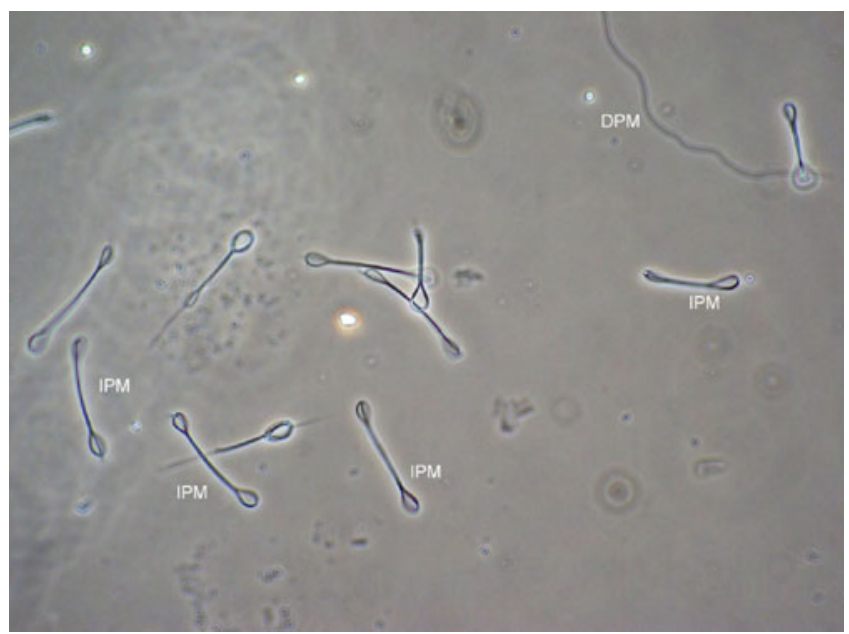


Table I. Relationship between observed semen parameters of honeybee semen.

\begin{tabular}{|c|c|c|c|c|c|c|c|c|c|}
\hline \multicolumn{2}{|c|}{$\begin{array}{l}\text { Observed semen parameters } \\
(\%)\end{array}$} & \multirow[t]{2}{*}{ SYBR-14/PI } & \multirow[t]{2}{*}{ Water test } & \multicolumn{2}{|c|}{$\begin{array}{l}\text { HOST } \\
50 \text { mOsm }\end{array}$} & \multicolumn{2}{|c|}{$\begin{array}{l}\text { HOST } \\
100 \mathrm{mOsm}\end{array}$} & \multicolumn{2}{|c|}{$\begin{array}{l}\text { HOST } \\
150 \mathrm{mOsm}\end{array}$} \\
\hline & & & & $30 \mathrm{~min}$ & $60 \mathrm{~min}$ & $30 \min$ & $60 \mathrm{~min}$ & $30 \mathrm{~min}$ & $60 \mathrm{~min}$ \\
\hline \multicolumn{2}{|l|}{ Motility } & $<0.001$ & $<0.001$ & $<0.001$ & $<0.001$ & $<0.001$ & $<0.001$ & $<0.001$ & $<0.001$ \\
\hline \multicolumn{2}{|l|}{ SYBR-14/PI } & - & $<0.001$ & $<0.001$ & $<0.001$ & $<0.01$ & $<0.01$ & NS & NS \\
\hline \multicolumn{2}{|l|}{ Water test } & & - & NS & NS & $<0.05$ & $<0.01$ & $<0.001$ & $<0.001$ \\
\hline \multirow[t]{2}{*}{ HOST 50 mOsm } & $30 \mathrm{~min}$ & & & - & $<0.01$ & $<0.001$ & $<0.001$ & $<0.001$ & $<0.001$ \\
\hline & $60 \mathrm{~min}$ & & & & - & NS & NS & $<0.001$ & $<0.001$ \\
\hline \multirow[t]{2}{*}{ HOST 100 mOsm } & $30 \mathrm{~min}$ & & & & & - & NS & $<0.001$ & $<0.01$ \\
\hline & $60 \mathrm{~min}$ & & & & & & - & $<0.001$ & $<0.001$ \\
\hline HOST 150 mOsm & $30 \mathrm{~min}$ & & & & & & & - & $<0.05$ \\
\hline
\end{tabular}

NS not significant, SYBR-14/PI live spermatozoa determined by SYBR-14/PI, HOST hypo-osmotic swelling test

min incubation was lower than 30-min incubation $(P<0.05)$. The percentage of swollen-tail spermatozoa obtained with the HOS test at $100 \mathrm{mOsm}$ was not affected by the incubation time $(P>0.05)$.

The Pearson correlation coefficients are shown in Table II. There were no significant correlations between sperm motility and the other studied parameters except the water and HOS tests at $150 \mathrm{mOsm}(P<0.05)$. A statistical correlation was found between the results of the water test and the results of the HOS tests at 100 and $150 \mathrm{mOsm}$ incubated for $30 \mathrm{~min}(P<0.01)$.

\section{DISCUSSION}

The development of simple, reliable, and lowcost tests to assess the functional integrity of honeybee semen should be useful in the diagnosis of sperm quality. The commonly used staining test (SYBR-14/PI and eosin/nigrosin) measures only the structural integrity of the sperm membrane (Garner and Johnson 1995; Chalah and Brillard 1998). Several physiological processes during fertilization demand a functionally intact membrane (Jeyendran et al. 1984). In this study, a series of experiments using endosmosis-negative tests that determine changes in sperm membrane function (i.e., the HOS and water tests) were conducted to assess the reactivity of honeybee spermatozoa. These tests are based on the swelling ability of functionally intact spermatozoa after exposure to a hypo-osmotic solution (Jeyendran et al. 1984; Ahmadi and Soon-Chye 1992; Nur et al. 2004, 2005).

The HOS and water tests challenge the resistance of sperm structures and can better identify viable sperm compared to measures of sperm motility or acrosomal status (Perez-Llano et al. 2009). The response of honeybee spermatozoa to the hypo-osmolar solution was similar to those reported for human (Jeyendran et al. 1984; Bahamondes et al. 2001), bovine (Nur et al. 2003), caprine (Nur et al. 2005), canine (Kumi 1993; Nur et al. 2004), and ovine (Soylu et al. 2007) spermatozoa. Subjecting honeybee spermatozoa to the hypo-osmolar solution caused morphologic changes, evidenced by the curling/swelling of the tail and main pace of spermatozoa. The degree of curling/swelling varied significantly among spermatozoa samples. In this study, the percentages of swollen spermatozoa obtained with the water and HOS tests were higher than the percentages of viable and motile cells $(P<0.001)$. Although the sperm viability assay (SYBR-14/PI) is based on the principle that dead cells with damaged membrane absorb stain based on their impermeability to PI (manufacture product information), the water and HOS tests evaluate the functional integrity of the sperm plasma membrane based on its osmotic 


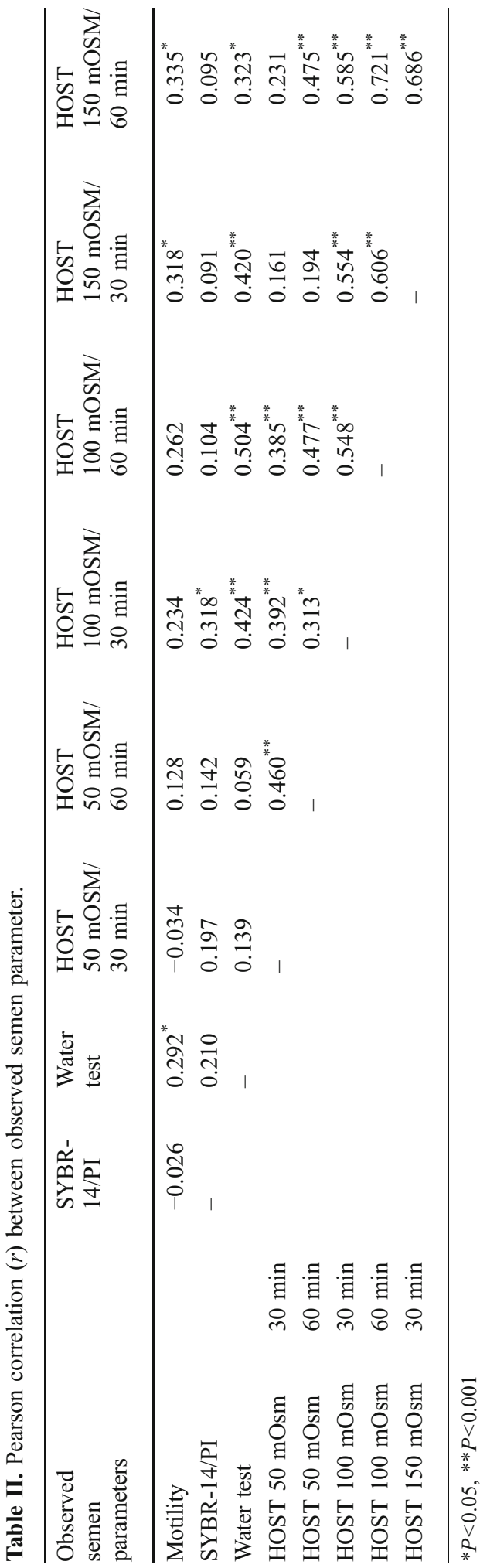

properties (Jeyendran et al. 1984). The percentages of swollen-tail spermatozoa obtained with the water and HOS tests have been shown to be correlated positively with the measured motility in bucks (Nur et al. 2005). This study demonstrates that the water and HOS tests can also be used to evaluate sperm motility in honeybees $(P<0.05)$. These findings differ from those reported by Lin et al. (1998) and Lomeo and Giambersio (1991); they found no correlation between the motility and water tests for human spermatozoa. The high correlations between the percentages of motile spermatozoa and spermatozoa reactive to the HOS test were expected because sperm motility partly depends on the membrane functional integrity and other biochemical activities, such as sperm metabolism (Jeyendran et al. 1984). These divergent results could be partly attributable to the subjectivity of motility observation.

The percentage of swollen-tail spermatozoa in humans was found to be consistently higher than the percentage of viable cells unstained with eosin Y (Verheyen et al. 1997). In the present study, the proportion of viable spermatozoa obtained using the SYBR-14/PI treatment was lower than the proportion of swollen-tail spermatozoa measured in the water and HOS tests. This result might be explained by an analysis of boar spermatozoa by Perez-Llano et al. (2009). Those authors found that all short HOS test-negative sperm (unswollen-tail spermatozoa) had died, but a short HOS test combined with viability tests (sHV) revealed that approximately $18 \%$ of the dead spermatozoa had an intact plasma membrane.

It is essential that the recommended techniques for semen evaluation be simple, include as few steps as possible, and not require costly equipment (Bjorndahl et al. 2003). Many semen characteristics are affected by mishandling during laboratory evaluation. Dye exclusion protocols, such as eosin staining, differ considerably with regard to the type and concentration of dye used in the staining solution, the duration of exposure to dye, the degree of dilution of semen (which affects the free concentration of dye), and osmotic conditions (e.g., the duration of exposure and type of dilution medium, which affect sperm volume and viability) 
(Bjorndahl et al. 2003). For stain-based evaluation, the stain and all equipments should be prewarmed. In addition, stained smears should be rapidly dried for optimal definition of sperm cell morphology, preferably on a temperaturecontrolled slide warmer or microscope warm stage (Ileri et al. 2000). The accuracy of SYBR14/PI results depends on the stains and sample concentration and on the amount of time the slides are left to dry. A longer drying time results in a higher number of dead spermatozoa; some spermatozoa lose their structural integrity during drying and are thus stained by PI. Taylor et al. (2009) used SYBR-14/PI to assess the viability of honeybee semen by scoring 100 cells twice per sample. Results were accepted only if the duplicate counts differed by less than $5 \%$; otherwise, samples were recounted using the same method.

In conclusion, subjecting honeybee spermatozoa to hypo-osmotic solution result in clearly identifiable swollen-tail spermatozoa. The percentages of swollen-tail spermatozoa obtained with the water and HOS tests were higher than the percentages of viable and motile spermatozoa. Similar results were obtained with the water and HOS tests using $50 \mathrm{mOsm}$. The HOS and water tests are simple methods to evaluate the functional integrity of the bee sperm plasma membrane, and they may be a useful addition to standard methods of semen evaluation in mammals. The water test in particular is more practical in evaluating honeybee semen than either the HOS test or SYBR-14/PI.

L'utilisation du test hypo-osmotique, du test de l'eau et de la coloration supravitale dans l'évaluation du sperme des mâles d'abeilles.

Sperme / abeille / test hypo-osmotique / viabilité/ qualité

Ein Beitrag zur Anwendbarkeit des hyposmotischen Schwellungstests, des Wassertests und einer Supravitalfärbung zur Evaluierung der Qualität von Drohnensperma

Bienensperma / HOS-Test / Wassertest / Viabilität

\section{REFERENCES}

Ahmadi, A., Soon-Chye, N.G. (1992) The single sperm curling test, a modified hypo-osmotic swelling test, as a potential technique for the selection of viable sperm for intracytoplasmic sperm injection. Fertil. Steril. 68, 346-350

Bahamondes, L., Fazano, F., De Lucio, M.A., Neves, P.A., Bottcher, L.F., Lorenzetti, G.B. (2001) Evaluation of human sperm membrane integrity using the water test and the hypoosmotic test. Andrologia 33, 75-77

Bjorndahl, L., Soderlund, I., Kvist, U. (2003) Evaluation of the one-step eosin-nigrosin staining technique for human sperm vitality assessment. Hum. Rep. 18, 813-816

Chalah, T., Brillard, J.P. (1998) Comparison of assessment of fowl sperm viability by eosin-nigrosyn and dual fluorescence (SYBR-14). Theriogenology 50, 487-493

Collins, A.M., Donoghue, A.M. (1999) Viability assessment of honey bee, Apis mellifera sperm using dual fluorescent staining. Theriogenology 51, 1513-23

Fuse, H., Ohta, S., Sakamoto, M., Kazama, T., Katayama, T. (1993) Hypoosmotic swelling test with a medium of distilled water. Arch. Androl. 30, 111-116

Garner, D.L., Johnson, L.A. (1995) Viability assessment of mammalian sperm using SYBR-14 and propidium iodide. Biol. Rep. 53, 276-284

Hafez, E.S.E. (1993) Reproduction in farm animals. In: Hafez, E.S.E. (ed.) Semen evaluation, pp. 405-423. Lea and Febiger, Philadelphia

Ileri, I.K., Ak, K., Pabuccuoglu, S., Birler, S. (2000) Reproduksiyon ve sun'i Tohumlama. Istanbul Üniv. Vet. Fak. Yayini. Ders Notu No: 23

Jeyendran, R.S., Van Der Ven, H.H., Perez-Pelaez, M., Crabo, B.G., Zaneveld, L.J.D. (1984) Development of an assay to assess the functional integrity of the human sperm membrane and its relationship to other semen characteristics. J Reprod Fert 70, 219-228

Kumi, D.J. (1993) Subjecting canine semen to hypoosmotic test. Theriogenology 39, 1279-1289

Lin, M.H., Morshedi, M., Srisombut, C., Nassar, A., Oehninger, S. (1998) Plasma membrane integrity of cryopreserved human sperm: an investigation of the results of the hypoosmotic swelling test, the Water test, and eosin-Y staining. Fertil. Steril. 70, 148-155

Lomeo, A.M., Giambersio, A.M. (1991) Water-test': a simple method to assess sperm-membrane integrity. Int. J. Androl. 14, 278-282

Malmgren, L. (1992) Sperm morphology in stallions in relation to fertility. Acta Vet. Scand. 88, 39-47

Nur, Z., Dogan, I., Soylu, M.K., Ak, K. (2003) Effect of different thawing procedures on the quality of bull semen. Rev. Med. Vet. 154, 487-490

Nur, Z., Dogan, I., Yerlikaya, H., Soylu, M.K. (2004) Relationship between the canine sperm membrane 
integrity and other semen characteristics. Indian Vet J. 81, 1119-1121

Nur, Z., Dogan, I., Gunay, U., Soylu, M.K. (2005) Relationships between sperm membrane integrity and other semen quality characteristics of the Saanen goat bucks. Bull. Vet. Inst. Pulawy 49, 183-188

Perez-Llano, B., Sala, R., Reguera, G., Garcia-Casado, P. (2009) Changes in subpopulations of boar sperm defined according to viability and plasma and acrosome membrane status observed during storage at 15 degrees $\mathrm{C}$. Theriogenology 71, 311-317

Soylu, M.K., Nur, Z., Ustuner, B., Dogan, I., Sagirkaya, H., Gunay, U., Ak, K. (2007) Effects of various cryoprotective agents and extender osmolality on post-thaw ram semen. Bull. Vet. Inst. Pulawy 51, 241-246

Taylor, M.A., Guzmán-Novoa, E., Morfin, N., Buhr, M. M. (2009) Improving viability of cryopreserved honey bee (Apis mellifera L.) sperm with selected diluents, cryoprotectants, and semen dilution ratios. Theriogenology 72, 149-159

Verheyen, G., Joris, H., Crits, K., Nagy, Z., Tournaye, H., Van Steirteghem, A. (1997) Comparison of different hypo-osmotic swelling solutions to select viable immotile spermatozoa for potential use in intracytoplasmic sperm injection. Hum. Reprod. Updat. 3, 195-203 